Tropical Journal of Pharmaceutical Research June 2016; 15 (6): 1197-1203

ISSN: $1596-5996$ (print); 1596-9827 (electronic) (C) Pharmacotherapy Group, Faculty of Pharmacy, University of Benin, Benin City, 300001 Nigeria.

All rights reserved.

\title{
Effect of inulin supplementation in male mice fed with high fat diet on biochemical profile and $\alpha$-amylase gene expression
}

\author{
Zahra Pouyamanesh ${ }^{1}$, Mahsa M Amoli ${ }^{2}$, Parichehreh Yaghmaei ${ }^{1}$ and Azadeh \\ Ebrahim-Habibi ${ }^{3 *}$ \\ ${ }^{1}$ Department of Biology, Science and Research Branch, Islamic Azad University, ${ }^{2}$ Endocrinology and Metabolism Research \\ Center, Endocrinology and Metabolism Clinical Sciences Institute, ${ }^{3}$ Biosensor Research Center, Endocrinology and Metabolism \\ Molecular-Cellular Sciences Institute, Tehran University of Medical Sciences, Tehran, Iran
}

*For correspondence: Email: yaghmaei_p@srbiau.ac.ir; Tel: +98 912 2010222; Fax: +98 2122363520

Received: 8 December 2015

Revised accepted: 7 May 2016

\begin{abstract}
Purpose: To evaluate the preventive and therapeutic effects of inulin supplementation in Naval Medical Research Institute (NMRI) male mice fed with high fat diet.

Methods: NMRI male mice $(n=36)$ were divided into three groups. Control $(C 1)$, obese (O1) and experimental mice (E1) were fed during 8 weeks as follows: $C 1$ with normal rodent pellet, 01 with high fat diet, and E1 with high fat diet plus $20 \%$ inulin. C2, O2, and E2 were fed as follows: C2 with normal rodent pellets for 12 weeks; $\mathrm{O} 2$ with high fat diet during 8 weeks and switched to normal rodent pellet during next 4 weeks; and E2 with high fat diet over a period of 8 weeks and switched to normal rodent pellet plus $20 \%$ inulin for 4 weeks. Body weight, serum glucose, triglycerides, total cholesterol, high density lipoprotein (HDL), low density lipoprotein ( $L D L)$, and hepatic $\alpha$-amylase gene expression were measured.

Results: Groups receiving high fat diet showed higher weight (30.71 $\pm 0.66 \mathrm{~g}$ in $02, p<0.001)$, nonfasting blood glucose levels (257.69 $\pm 5.10 \mathrm{mg} / \mathrm{dl}$ in O2, $p<0.001), \mathrm{TG}(282.15 \pm 1.83 \mathrm{mg} / \mathrm{dl}$ in O2, ( $p<$ $0.001)$ ), and cholesterol levels (335.72 $\pm 2.23 \mathrm{mg} / \mathrm{dl}$ in O2, $(p<0.001))$, compared with control. In C2 group, mean body weight was $25.71 \pm 0.54 \mathrm{~g}$, non-fasting blood level $161.54 \pm 4.48 \mathrm{mg} / \mathrm{dl}$, TG level $214.29 \pm 5.54 \mathrm{mg} / \mathrm{dl}$, and cholesterol level $164.29 \pm 4.57 \mathrm{mg} / \mathrm{dl}$. Compared to obese group, mice receiving inulin showed lower blood glucose levels (223.10 $\pm 8.7 \mathrm{mg} / \mathrm{dl}$ in E2, $p<0.001)$, body weight (27.86 $\pm 0.57 \mathrm{~g}$ in E2, $p<0.001)$, TG (232.14 $\pm 4.02 \mathrm{mg} / \mathrm{dl}$ in E2, $p<0.001)$ and cholesterol $(249.97 \pm$ 2.28 in E2, $p<0.001)$. A slight decrease in hepatic $\alpha$-amylase gene expression was observed only in E1.

Conclusion: Besides its sweetening properties, inulin may also find use as a potential anti-obesity compound.
\end{abstract}

Keywords: High-fat diet, Inulin, Obesity, Blood glucose, Biochemical profile

Tropical Journal of Pharmaceutical Research is indexed by Science Citation Index (SciSearch), Scopus, International Pharmaceutical Abstract, Chemical Abstracts, Embase, Index Copernicus, EBSCO, African Index Medicus, JournalSeek, Journal Citation Reports/Science Edition, Directory of Open Access Journals (DOAJ), African Journal Online, Bioline International, Open-J-Gate and Pharmacy Abstracts

\section{INTRODUCTION}

The World Health Organization (WHO) defines overweight and obesity as "extreme accumulation of body fat to an extent where it may have adverse effects on the health of the individual" [1]. Considering the global prevalence of obesity and its deleterious consequences, which ultimately leads to higher mortality rates, numerous studies are aiming at preventing and 
treating this condition. In order to counteract obesity, lifestyle change is recommended and includes the use of healthier diets [2] and increase of physical activity. [3]. However, implementing such changes in patients' lives is usually difficult, and alternative therapeutic means such as drugs, are widely sought after [4]. The use of artificial sweeteners has been proposed as a way to help weight control through lessening energy intake [5]. The short-term efficacy of these compounds is clear, but in the long term, some studies report an actual weight gain associated with these compounds' consumption [6].

Recently, a potentially more elaborated mechanism of these substances has been proposed. Based on this suggestion, these compounds would act on specific receptors, which are present in the taste buds, and in the gastrointestinal tract [7].

Inulin is a polysaccharide composed of fructose units, found in a wide variety of plants, and commercially extracted from chicory roots [8]. Fructose was previously suggested as an alternate sweetener to saccharin [9], and assumed to be a safe product when consumed moderately [10]. However, recent studies highlight the occurrence of severe adverse effects linked to its consumption [11,12]. On the other hand, inulin is considered as a "dietary fiber" which could be proposed as a potentially healthier alternative to fructose [13].

In this study, we have tested the effect of inulin consumption in a mouse model fed with a high fat diet, in order to observe the potential effect of the compound on various obesity-linked factors.

\section{EXPERIMENTAL}

\section{Animals and experimental protocol}

Male NMRI mice (six weeks old) weighing $20 \pm 5$ $\mathrm{g}$ were purchased from the Laboratory of Animal Research Center of the Qom Branch of Jahad Daneshgahi (Iran). The mice were exposed to light/dark cycle of $12 \mathrm{~h}$, and housed in standard cages at $25^{\circ} \mathrm{C}$. After one week of adaptation to the laboratory conditions, mice were randomly divided into six groups $(\mathrm{n}=6$ in each group).These groups were treated in two different settings. In both settings, mice had unrestricted access to food. In the first setting, the duration of experiment was eight weeks for the three groups $\mathrm{C} 1, \mathrm{O} 1$, and $\mathrm{E} 1$. In the second setting, the total experiment duration was 12 weeks for the three groups C2, O2 and E2.

In the first setting, the C1 group (control group), received standard rodent chow, the $\mathrm{O} 1$ group (obese group) received high fat diet, and the E1 group (experimental group) received high fat diet and inulin. Inulin (from chicory, obtained from Sigma-Aldrich, St. Louis, MO, USA) was dissolved at $20 \%$ in distilled water and $1 \mathrm{~mL}$ of this solution was given to each mouse by gavage. The high-fat diet was prepared according to previously reported methods $[14,15]$ and consisted of $150 \mathrm{~g}$ of mouse pellet standard chow, $100 \mathrm{~g}$ roasted peanuts, $100 \mathrm{~g} \mathrm{milk}$ chocolate, $50 \mathrm{~g}$ sesame crackers and $20 \mathrm{~g}$ roasted sesame (Table 1 ). In addition, the obese group was fed $420 \mathrm{~g}$ creamy biscuits (1388 cal) weekly.

In the second setting, the C2 group (control group) was given standard rodent chow during the whole experimental period (12 weeks). The O2 group (obese group) received high fat diet during the first 8 weeks, and was then switched to normal rodent chow for the next four weeks (weeks 9-12 of experiment). The E2 group (experimental group) received high fat diet during the first 8 weeks, and was switched to normal rodent chow and inulin (prepared as mentioned above) for the next four weeks (weeks 9-12 of experiment).

Table 1: Composition of normal and high fat diet used in the study

\begin{tabular}{lcccc}
\hline $\begin{array}{l}\text { Diet } \\
\text { type }\end{array}$ & $\begin{array}{c}\text { Fat } \\
\mathbf{( \% )}\end{array}$ & $\begin{array}{c}\text { Carbohydrate } \\
\mathbf{( \% )}\end{array}$ & $\begin{array}{c}\text { Protein } \\
\mathbf{( \% )}\end{array}$ & $\begin{array}{c}\text { Total } \\
\text { Energy } \\
\text { (cal/g) }\end{array}$ \\
\hline $\begin{array}{l}\text { Normal } \\
\text { High } \\
\text { fat }\end{array}$ & 11.40 & 62.80 & 25.80 & 3.01 \\
\hline
\end{tabular}

The body weight of mice was measured at the end of the eighth and twelfth weeks in first and second settings respectively. At the end of the experiment, the animals were anesthetized and sacrificed Blood samples were collected and immediately centrifuged at $4{ }^{\circ} \mathrm{C}$ in anticoagulantcoated centrifuge tubes (Greiner, Germany) to collect the serums. All experimental protocols were performed in accordance with the international guidelines set out in the Guide for the Care and Use of Laboratory Animals (Institute of Laboratory Animal Resources) [16]. Ethical approval (no. 176948) was provided by the Ethics Committee of the Department of Animal Biology at the Science Faculty of Science and Research Branch, Islamic Azad University, Iran. 


\section{Determination of biochemical parameters}

Total cholesterol, triglyceride, HDL, LDL and blood glucose of animals serum were measured using appropriate biochemical kits based on enzymatic methods (Pars Azmoon, Iran) as per manufacturer's instructions. The animals were not fasted, and all biochemical parameters are indicative of a non-fasting state.

\section{Determination of $\alpha$-amylase gene expression}

Livers were separated after mice were sacrificed. Liver tissue was washed 3 times by cold PBS and $500 \mathrm{mg}$ weighed tissue was transferred to sterile microtubes (Eppendorf, Germany). $1 \mathrm{ml}$ of Tris/ $\mathrm{HCl}$ (TB; pH 7.5, $20 \mathrm{mM}$ ) with $0.3 \mathrm{mmol} / \mathrm{L}$ of phenylmethylsulfonyl fluoride (PMSF) and 1 $\mathrm{mmol} / \mathrm{L}$ of benzamidine chloride (all chemicals from Merck, Germany), were added to the tubes and the tissues were homogenized. The suspension was centrifuged for $20 \mathrm{~min}$ at 1500 $\mathrm{rpm}$ and supernates were separated. The resulted extracts were stored at $-80^{\circ} \mathrm{C}$ for RNA extraction. Total RNA was extracted from hepatocytes by using Trizol (Invitrogen, USA) in a standard protocol and RNA purity was assessed by the $260 / 280$ ratio by a NanoDrop 2000C (Thermo Scientific, USA). From each sample, up to $250 \mathrm{ng}$ of total RNA was subjected to complementary DNA synthesis random hexanucleotide primers and Revert AID First Strand cDNA Synthesis kit (Fermantas, Vilnius, Lithuania). Quantitative RT-PCR (duplicate assays) was performed on the obtained cDNA and HPRT housekeeping gene was used as internal control. The primer pair sequences were 5'-GTG ATT AGC GAT GAT GAA CCA G-3', 5'GCA AGT CTT TCA GTC CTG TCC-3' for HPRT and 5'-AAGATGTCCTACTTAAAGAACTGG-3', 5'-ACCCGTGTGAAACCATAAGG-3'. Reaction was set by mixing 30ng cDNA, $10 \mu \mathrm{L}$ RT2 RealTimeTM SYBR Green/ROX PCR Master, primer pairs and nuclease-free water to $20 \mu \mathrm{L}$. Thermal condition was used for 40 cycles consisting of initial polymerase activation step at $95{ }^{\circ} \mathrm{C}$ for 10 min, followed by cycles of denaturation at $95{ }^{\circ} \mathrm{C}$ for $5 \mathrm{~s}$, and finally annealing and extension at 61 ${ }^{\circ} \mathrm{C}$ for $40 \mathrm{~s}$. Subsequently for melting curve analysis, the PCR was continued by further steps including: $95{ }^{\circ} \mathrm{C}$ for $15 \mathrm{~s}, 61{ }^{\circ} \mathrm{C}$ for $15 \mathrm{~s}$, and 95 ${ }^{\circ} \mathrm{C}$ for $15 \mathrm{~s}$. For all steps, ABI step One TM quantitative PCR system was used (Applied Biosystems, CA, USA).

\section{Statistical analysis}

Data are reported as mean \pm standard deviation (SD), and were analyzed by SPSS, (version 15.0, SPSS Inc., USA) with the use of Analysis of
Variance method (ANOVA), Fisher's least significant difference (LSD) and Tukey's test. Significance level was set at $p<0.05$.

\section{RESULTS}

\section{Body weight}

A significant weight gain was observed in the obese group $\mathrm{O} 1$ at week 8 of the experiment in comparison to its control group $\mathrm{C} 1(p<0.001)$. The $\mathrm{O} 2$ group showed also a significant weight gain at week 12 of experiment in comparison to its control group (C2) $(p<0.001)$ (Figure 1). On the other hand, consumption of inulin, both in the preventive and treating modes (E1 and E2 respectively), caused a decrease in weight gain $(\mathrm{E} 1, p<0.05)$, or an increase in weight loss (E2, $p<0.001)$ compared to the respective untreated obese groups (O1 and $\mathrm{O} 2$, Figure 1). Body weight of the $E 1$ group has a significant difference with the C1 group $(p<0.001)$ and body weight of E2 group has a significant difference with the $\mathrm{C} 2$ group $(p<0.05)$. This comparison of $E 1$ and $E 2$ groups with their respective control groups show that taking inulin could not revert the obese state back to normal.

\section{Blood glucose}

On consumption of high fat diet, blood glucose levels had significantly increased in the obese groups $\mathrm{O} 1$ and $\mathrm{O} 2$ compared to their respective control groups $(p<0.001$, Fig 2). Inulin supplementation led to lower levels of blood glucose in both E1 and E2 groups in comparison to obese groups ( $p<0.001$, Figure 2). However, in E1 and E2 groups, blood glucose levels were higher than their respective control groups $(p<$ 0.001, Figure 2).

\section{Lipid profile}

The serum triglyceride (TG), LDL, and cholesterol levels of the $\mathrm{O} 1$ and $\mathrm{O} 2$ groups became significantly higher than their respective control groups, while HDL levels were lower $(p<$ 0.001 , Figure 3 ). In the E1 and E2 groups that were taking inulin, the lipid profile was different with the obese groups. More specifically, for TG, cholesterol, and LDL, E groups had significant differences relative to their obese counterparts $(p$ $<0.001$ for TG and cholesterol, and $p<0.01$ for LDL). TG, cholesterol and LDL levels of $E$ groups showed significant difference with their respective control groups. The $p$-value was $p<$ 0.001 in all groups, save for E2 compared to $C 2$ were it was $p<0.01$. HDL levels of the E1 group 
had no significant difference with 01 , while in the E2 group, HDL levels had increased significantly $(p<0.001$ in comparison to O2) (Figure 3).

\section{a-Amylase gene expression}

Obese groups showed a significant increase in their liver alpha-amylase gene expression levels $(p<0.01$ in comparison to control groups, Figure

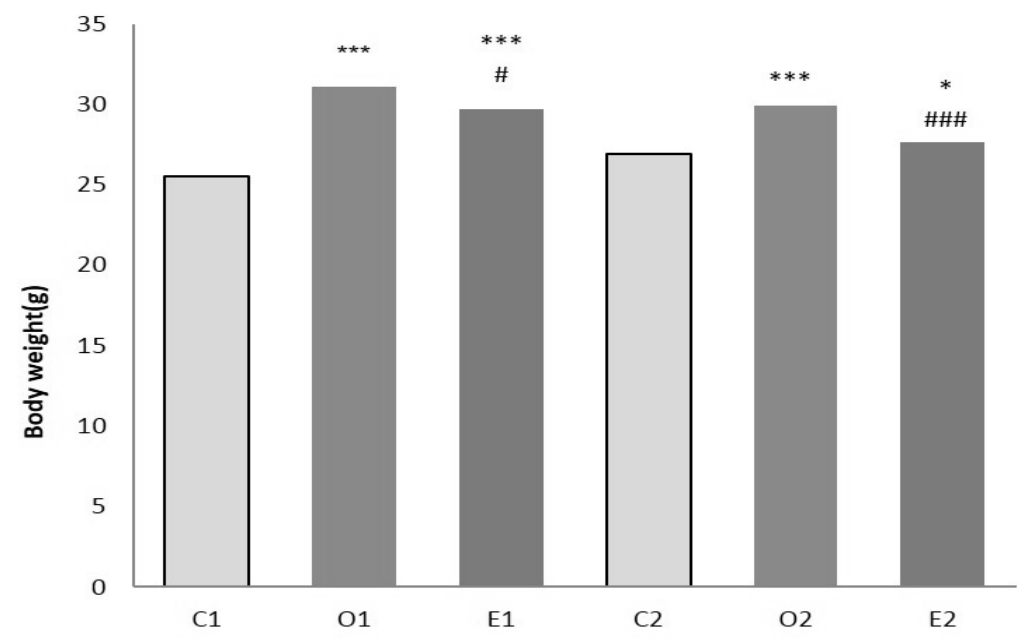

Figure 1: Effect of inulin on mice body weight. $\mathrm{C1}, \mathrm{O} 1$, and $\mathrm{E} 1$ : groups of the first setting, where the experiment duration was 8 weeks. $\mathrm{C} 1$ received normal rodent food, $\mathrm{O} 1$ received high fat diet, and $\mathrm{E} 1$ received high fat diet and $20 \%$ inulin. C2, O2, and E2: groups in the second setting, where the total period of the experiment was 12 weeks. C2 received normal rodent food for 12 weeks, O2 received high fat diet for 8 weeks and normal rodent food for the remaining 4 weeks, E2 received high fat diet for 8 weeks and normal rodent food plus $20 \%$ inulin for the remaining 4 weeks. Data are shown as mean $\pm S D .{ }^{* *} p<0.001 ;{ }^{*} p<0.05$ compared to control group (C); $\# \#$ \# $<0.001 ; \# p<0.05$ compared with the obese group $(0)$

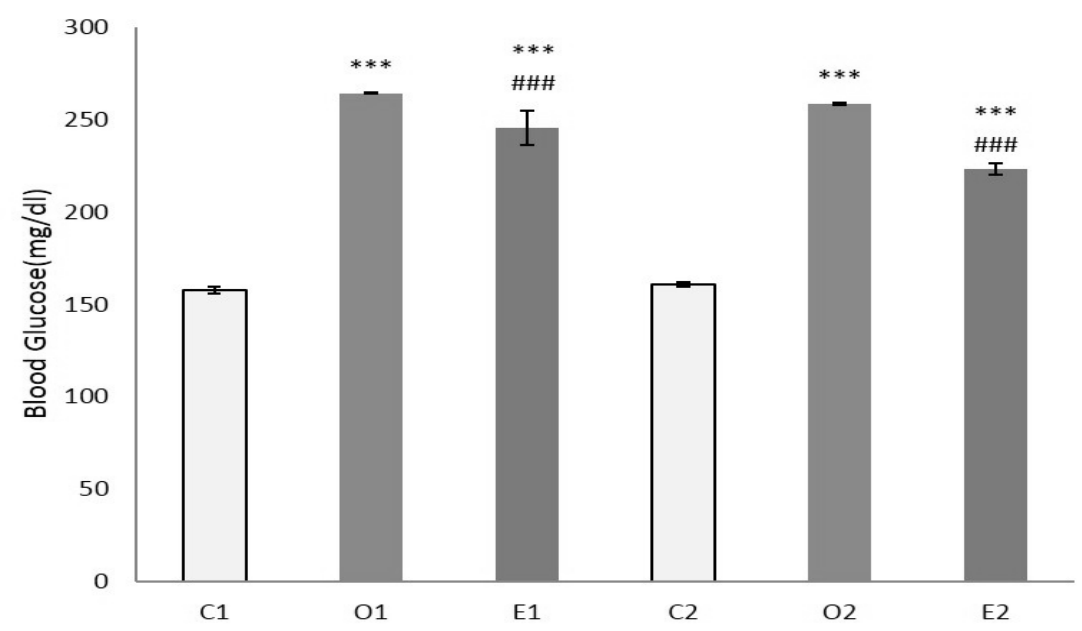

Figure 2: Effect of inulin supplementation on the serum blood glucose (mg/dl) in mice. $\mathrm{C} 1, \mathrm{O} 1$, and $\mathrm{E} 1$ : groups of the first setting, where the experiment duration was 8 weeks. $\mathrm{C} 1$ received normal rodent food, $\mathrm{O} 1$ received high fat diet, and E1 received high fat diet and $20 \%$ inulin. C2, O2, and E2: groups in the second setting, where the total period of the experiment was 12 weeks. C2 received normal rodent food for 12 weeks, O2 received high fat diet for 8 weeks and normal rodent food for the remaining 4 weeks, E2 received high fat diet for 8 weeks and normal rodent food plus $20 \%$ inulin for the remaining 4 weeks. Data are shown as mean \pm SD; ${ }^{* * *} p<0.001$ compared with the control group(C); \#\#p < 0.001 compared with the obese group (O) 

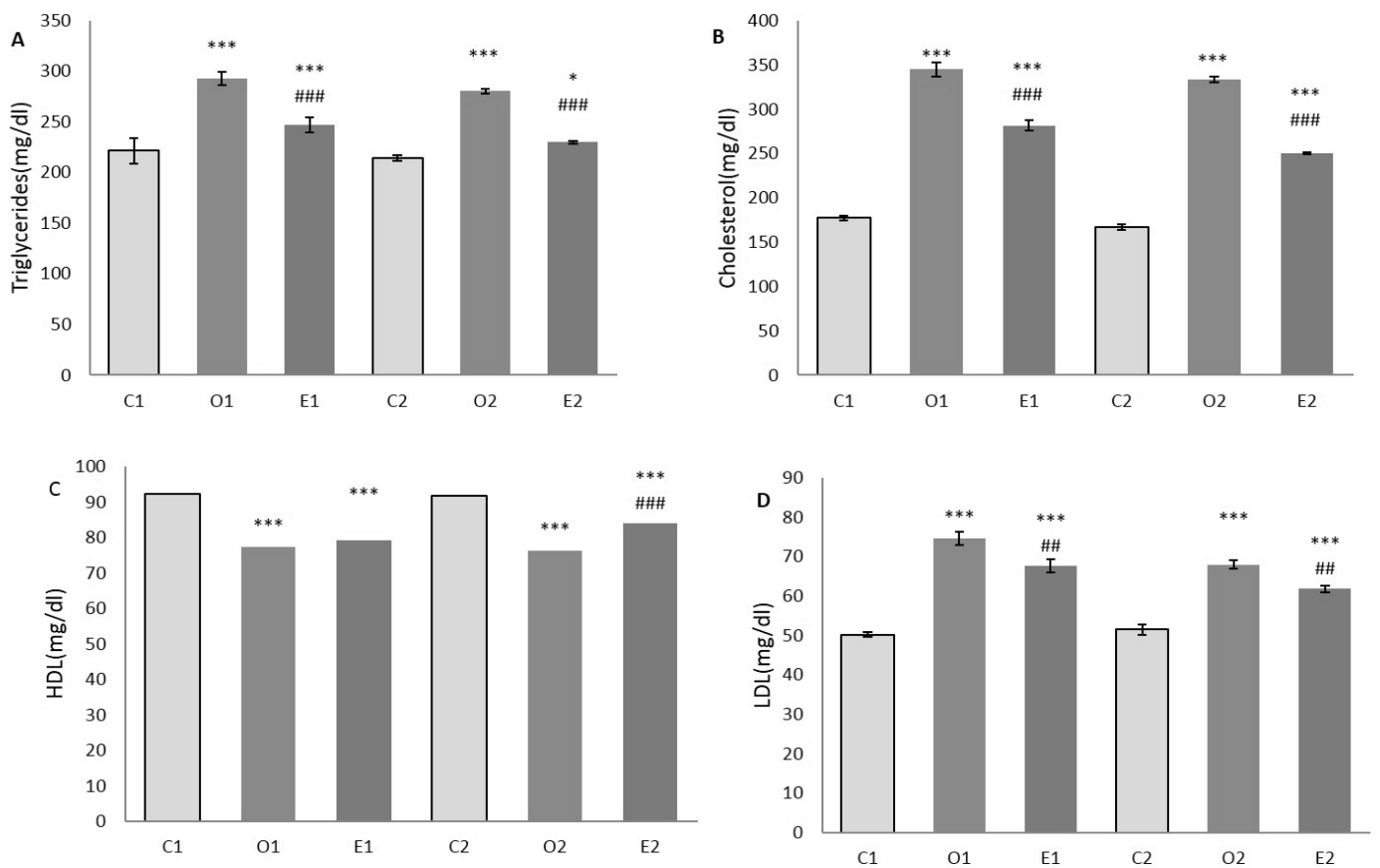

Figure 3: Effect of inulin supplementation on serum triglycerides (TG) (A), Cholesterol (B), and HDL (C) and LDL (D) in mice. C1, O1, and E1: groups of the first setting, where the experiment duration was 8 weeks. C1 received normal rodent food, $\mathrm{O} 1$ received high fat diet, and $\mathrm{E} 1$ received high fat diet and $20 \%$ inulin. C2, O2, and E2: groups in the second setting, where the total period of the experiment was 12 weeks. C2 received normal rodent food for 12 weeks, O2 received high fat diet for 8 weeks and normal rodent food for the remaining 4 weeks, E2 received high fat diet for 8 weeks and normal rodent food plus $20 \%$ inulin for the remaining 4 weeks. Data are shown as mean $\pm \mathrm{SD} ;{ }^{* * *} p<0.001$ compared with the control group $(\mathrm{C})$, ${ }^{* *} p<0.01$ compared with the control group, ${ }^{*} p<0.05$ compared with the control group, \#\# $p<0.001$ compared with the obese group, \#\# $p<0.01$ compared with the obese group, \#p<0.05 compared with the obese group

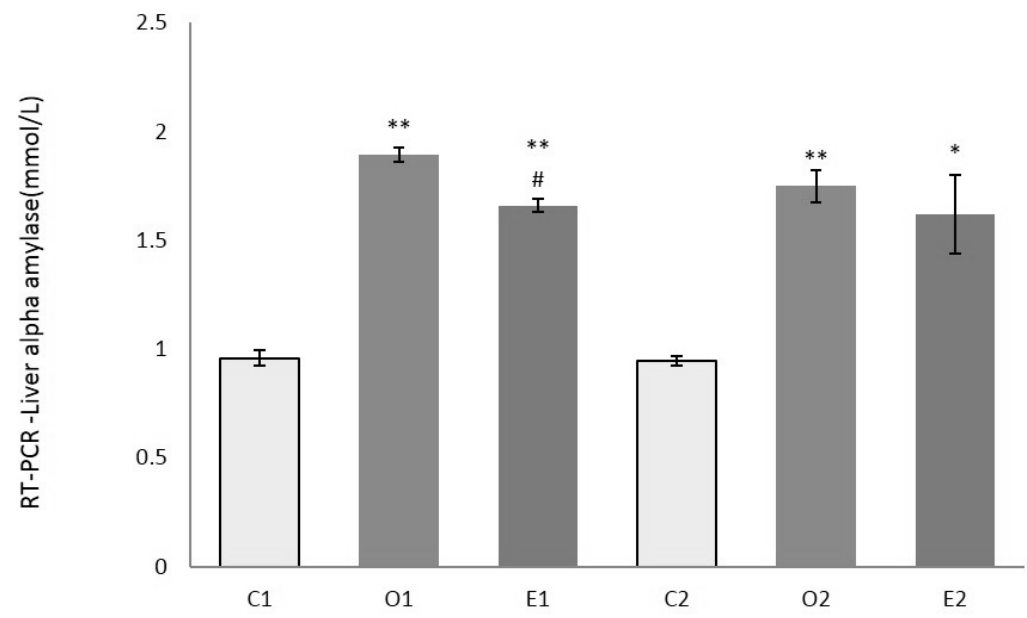

Figure 4: Effect of inulin onReal time-PCR with primers specific for alpha gene expression liver amylase Amy-1. C1, O1, and E1: groups of the first setting, where the experiment duration was 8 weeks. C1 received normal rodent food, $\mathrm{O} 1$ received high fat diet, and E1 received high fat diet and $20 \%$ inulin. C2, O2, and E2: groups in the second setting, where the total period of the experiment was 12 weeks. C2 received normal rodent food for 12 weeks, O2 received high fat diet for 8 weeks and normal rodent food for the remaining 4 weeks, E2 received high fat diet for 8 weeks and normal rodent food plus $20 \%$ inulin for the remaining 4 weeks. Data are shown as mean $\pm \mathrm{SD}$. ${ }^{*} p<0.05$ compared with the control (C) group, ${ }^{* *} p<0.01$ compared with the control (C) group, \# $p$ $<0.01$ compared with the obese $(01)$ group 


\section{DISCUSSION}

Inulin is an indigestible polymer formed by fructose units, and a "dietary fiber". Dietary fibers delay the processes of gastric emptying and small intestinal transit time [8]. Addition of dietary fibers to a high fat diet exerts a preventive effect on weight gain, and lowers blood glucose levels [17]. In our study, similar preventive effects were observed on weight gain and blood glucose levels of the mice that received inulin together with their high fat diet.

However, inulin is also showing a "therapeutic" effect, when it acts as an aid into dropping weight and decrease of blood glucose levels in mice that are already obese after consuming a high fat diet. Other properties have been previously reported for inulin including antioxidant and hepato protective activity [18], cyto protection against corticosteroid [19], and immune modulator function with a potential to be used in vaccines [20] or as an aid in cancer treatment [21]. As so, inulin may be considered to be a functional nutriment [22].

A very prominent feature of inulin is a prebiotic property, which is being related to different manifestations of its effect with regard to the gastrointestinal tract, including a beneficial effect on intestinal bacteria that may provide healthpromoting effect to their hosts [23]. The use of inulin has been shown to improve lipid metabolism in rats that were fed a high fat diet [24]. Our results are also showing that inulin can correct an impaired lipid profile.

Inulin is also a "prebiotic", which increases the growth and activity of specific intestinal bacteria. The result of prebiotic supplementation is an improvement of gastro-intestinal problems [23]. Numerous studies suggest a link between the gut microbiota composition and obesity. In many reports, a difference has been observed between the dominant microbiome phyla of obese and lean mice. Accordingly, changing the microbiota composition through direct administration of bacteria (probiotics) or indirect effect of prebiotics leads to weight loss [24]. In a recent study, the use of inulin has been shown to affect the gut microbiota of rats that were fed a high fat diet, and improve lipid metabolism [25]. Our results are similarly showing that inulin can correct an impaired lipid profile.

Finally, a slight inhibitory effect in alpha-amylase gene expression was observed when inulin was taken with a high-fat diet. The obese mice have elevated levels of alpha-amylase gene expression, and decreasing these levels may have an anti-obesity effect. However, this is a hypothesis that needs further verification in future studies.

\section{CONCLUSION}

Inulin, which has been observed to positively affect several unpaired biochemical parameters of obese mice, may be used as an adjuvant to other therapies, to achieve both preventive and therapeutic management of obesity.

\section{DECLARATIONS}

\section{Conflict of Interest}

No conflict of interest associated with this work.

\section{Contribution of Authors}

The authors declare that this work was done by the authors named in this article and all liabilities pertaining to claims relating to the content of this article will be borne by them.

\section{REFERENCES}

1. World Health Organization. Obesity and overweight. Fact sheet No. 311. Updated January 2015. World Health Organization. [Cited: 2015 November 20] Available from: http://www.who.int/mediacentre/factsheets/fs311/ en/

2. Schröder H. Protective mechanisms of the Mediterranean diet in obesity and type 2 diabetes. J Nutr Biochem 2007; 18: 149-160.

3. Thivel D, Duche P. Physical activity for weight loss in children: is there any compensatory mechanism? Pediatr Exerc Sci 2014; 26: 121-123.

4. Hainer V, Hainerová IA. Do we need anti-obesity drugs? Diabetes Metab Res Rev 2012; 28: 8-20.

5. Raben A, Richelsen B. Artificial sweeteners: a place in the field of functional foods? Focus on obesity and related metabolic disorders. Curr Opin Clin Nutr Metab Care 2012; 15: 597-604.

6. Tandel KR. Sugar substitutes: Health controversy over perceived benefits. J Pharmacol Pharmacother 2011; 2: 236-243.

7. Brown RJ, de Banate MA, Rother KI. Artificial sweeteners: a systematic review of metabolic effects in youth. Int J Pediatr Obes 2010; 5: 305-312.

8. Flamm G, Glinsmann W, Kritchevsky D, Prosky L, Roberfroid M. Inulin and oligofructose as dietary fiber: a review of the evidence. Crit Rev Food Sci Nutr 2001; 41: 353-362.

9. Koivisto VA. Fructose as a dietary sweetener in diabetes mellitus. Diabetes care. 1978; 1: 241-246.

10. Osei K, Falko J, Bossetti BM, Holland GC. Metabolic effects of fructose as a natural sweetener in the

Trop J Pharm Res, June 2016; 15(6): 1202 
physiologic meals of ambulatory obese patients with type II diabetes. Am J Med 1987; 83: 249-255.

11. Schultz A, Neil D, Aguila MB, Mandarim-de-Lacerda CA. Hepatic adverse effects of fructose consumption independent of overweight/obesity. Int J Mol Sci 2013; 14: 21873-21886.

12. Stanhope KL, Schwarz J-M, Havel PJ. Adverse metabolic effects of dietary fructose: results from the recent epidemiological, clinical, and mechanistic studies. Curr Opin Lipidol 2013; 24: 198-206.

13. Raninen K, Lappi J, Mykkanen H, Poutanen K. Dietary fiber type reflects physiological functionality: comparison of grain fiber, inulin, and polydextrose. Nutr Rev 2011; 69: 9-21.

14. Banakar F, Parivar K, Yaghmaei P, MohseniKouchesfehani $H$. The effects of embryo/neonate exposure to Orlistat in NMRI-mouse strain. Ann Biol Res 2013; 4: 300-311.

15. de Melo CL, Queiroz MG, Fonseca SG, Bizerra AM, Lemos TL, Melo TS, Santos FA, Rao VS. Oleanolic acid, a natural triterpenoid improves blood glucose tolerance in normal mice and ameliorates visceral obesity in mice fed a high-fat diet. Chem Biol Interact 2010; 185: 59-65.

16. Clark JD, Gebhart GF, Gonder JC, Keeling ME, Kohn DF. The 1996 guide for the care and use of laboratory animals. ILAR J 1997; 38: 41-48.

17. Wang ZQ, Zuberi AR, Zhang XH, Macgowan J, Qin J, Ye $X$, Son $L, W u Q$, Lian K, Cefalu WT. Effects of dietary fibers on weight gain, carbohydrate metabolism, and gastric ghrelin gene expression in mice fed a high-fat diet. Metab Clin Exp 2007; 56: 1635-1642.

18. Liu J, Lu JF, Wen XY, Kan J, Jin CH. Antioxidant and protective effect of inulin and catechin grafted inulin against CCl4-induced liver injury. Int $\mathrm{J}$ Biol Macromol 2015; 72: 1479-1484.

19. Li YF, Liu YQ, Yang M, Wang HL, Huang WC, Zhao YM, Luo ZP. The cytoprotective effect of inulin-type hexasaccharide extracted from Morinda officinalis on PC12 cells against the lesion induced by corticosterone. Life Sci 2004; 75: 1531-1538.

20. Petrovsky N, Cooper PD. Carbohydrate-based immune adjuvants. Expert Rev Vaccines 2010; 10: 523-537.

21. Korbelik M, Cooper PD. Potentiation of photodynamic therapy of cancer by complement: the effect of gammainulin. Br J Cancer 2007; 96: 67-72.

22. Prosky L. When is dietary fiber considered a functional food? Biofactors 2000; 12: 289-297.

23. Leenen $\mathrm{CH}$, Dieleman LA. Inulin and oligofructose in chronic inflammatory bowel disease. J Nutr 2007; 137: 2572S-2575S.

24. Krajmalnik-Brown R, llhan ZE, Kang D-W, JK DiBaise. Effects of Gut Microbes on Nutrient Absorption and Energy Regulation. Nutr Clin Pract. 2012; 27: 201-214.

25. Han K-H, Tsuchihira $H$, Nakamura $Y$, Nakamura $Y$, Shimada K, Ohba K, Aritsuka T, Uchino H, Kikuchi $H$, Fukushima M. Inulin-Type Fructans with Different Degrees of Polymerization Improve Lipid Metabolism but Not Glucose Metabolism in Rats Fed a High-Fat Diet Under Energy Restriction. Dig Dis Sci 2013; 58: $2177-$ 2186. 